Pobrane z czasopisma Annales H - Oeconomia http://oeconomia.annales.umcs.pl Data: 26/04/2023 13:41:22

DOI:10.17951/h.2018.52.2.61-69

\begin{tabular}{lcc}
\hline & A N N A L E S \\
UNIVERSITATIS MARIAE CURIE-SKŁODOWSKA \\
LUBLIN - POLONIA \\
VOL. LII, 2 & SECTIO H \\
\hline
\end{tabular}

Uniwersytet Warszawski. Wydział Nauk Ekonomicznych

\author{
DARIUSZ TADEUSZ DZIUBA \\ dziubadt@wne.uw.edu.pl
}

Technologia blockchain crowdfunding: zastosowania, korzyści i oczekiwania

The Blockchain Crowdfunding Technology: Usage, Benefits, and Expectations

Slowa kluczowe: crowdfunding; blockchain crowdfunding; Pierwotna Emisja Kryptowalut; alternatywne systemy finansowe

Keywords: crowdfunding; blockchain crowdfunding; Initial Coin Offering; alternative financial systems

Kod JEL: G24; G29; L17; O3; O16

Wstęp

Crowdfunding stał się jedną z typowych, alternatywnych metod finansowania przedsięwzięć (inwestycji). Polega na gromadzeniu środków finansowych (kapitału) $\mathrm{z}$,thumu” internetowych darczyńców, sponsorów, pożyczkodawców i inwestorów za pośrednictwem platformy elektronicznej. Różne określanie uczestników rynkowych transakcji wynika z odmiennych modeli funkcjonujących w praktyce. Zwykle wydziela się kilka podstawowych modeli crowdfundingu, takich jak:

- donacyjny bez nagradzania, zwany charytatywnym,

- donacyjny z nagradzaniem niefinansowym, zwany sponsorskim,

- pożyczkowy i mikro-pożyczkowy (mikro-kredytowanie), 
- inwestycyjny, w tym z nagradzaniem finansowym (np. akcjami),

- hybrydowy, integrujący wyżej wymienione podejścia ${ }^{1}$.

Przedmiotem analiz jest nowy model crowdfundingu, dopiero kształtujący się blockchain crowdfunding, w sposób odmienny od dotychczasowych bazujący na systemach zdecentralizowanych. Zaistniał on dzięki koncepcji „łańcuchów bloków”, dynamicznie wkraczających do zastosowań gospodarczych, zwłaszcza w sferze finansowej. Blockchain można wstępnie określić [Maletski, Delman, 2017, s. 3] jako strukturę danych, która umożliwia tworzenie cyfrowego rejestru transakcji i daje możliwość dzielenia się danymi w rozproszonej sieci komputerów. Według MarketsandMarkets [2016] rozmiary globalnego rynku blockchain szacowane są na 210,2 mln USD w 2016 r., z tendencją wzrostową do 2312,5 mln USD w 2022 r., z roczną stopą wzrostu CAGR (Compound Annual Growth Rate) 61,5\%.

Celem niniejszych rozważań jest charakterystyka modelu blockchain crowdfunding na tle rozwoju i zastosowań technologii blockchain. Uwypuklono obszary ich zastosowań wraz z identyfikacją (potencjalnych) korzyści z tym się wiążących oraz uwarunkowań. Na podstawie zaproponowanej metodyki dokonano oszacowania segmentu rynkowego blockchain crowdfunding wraz z charakterystyką głównych tendencji rozwojowych.

W kolejnych wątkach rozpatrywane są: koncepcja blockchain; zakres jej zastosowań w sferze finansowo-bankowej; istota modelu blockchain crowdfunding, w tym koncepcja sprzedaży kryptowalut (Initial Coin Offering - ICO) i jej implikacje. Dokonano także wydzielenia i oszacowania segmentu rynkowego blockchain crowdfunding wraz z charakterystyką głównych tendencji rynkowych. Wnioski zestawiono w podsumowaniu.

\section{Koncepcja blockchain}

Blockchain to metoda gromadzenia danych w oparciu o globalne, zdecentralizowane rejestry. Cyfrowe rekordy są grupowane w „bloki” (stąd nazwa koncepcji) i z użyciem złożonych algorytmów są kodowane, łączone w chronologicznym porządku, tzn. każdy blok następny jest integrowany z poprzednim [Taylor, 2016, s. 1]. Bardziej precyzyjną definicję proponuje K. Piech:

[...] blockchain (polski odpowiednik: „łańcuch bloków”) [...] to rozproszona baza danych, która zawiera stale rosnącą ilość informacji (rekordów) pogrupowanych w bloki i powiązanych ze sobą w taki sposób, że każdy następny blok zawiera oznaczenie czasu (timestamp), kiedy został stworzony, oraz link do poprzedniego bloku, będący zaszyfrowanym „streszczeniem” (hash) jego zawartości [...]. W ten sposób tworzony jest nierozerwalny

\footnotetext{
1 Nie dokonujemy tu charakterystyki wymienionych modeli, ponieważ szczegółowo zostały opisane w literaturze [zob. m.in. Dziuba, 2012].
} 
łańcuch bloków danych [...], dzięki niemu dokonanie jakiejkolwiek zmiany w zapisach historycznych (bez zmiany całej historii transakcji) jest niemożliwe [Piech (red.), 2016, s. 5].

Nowe rekordy są dodawane do rejestru przez użytkowników w ramach sieci peer-to-peer. Wydziela się zwykle dwie kategorie systemów: permissioned, udostępniane użytkownikom łańcucha za uprzednią zgodą (do zastosowań korporacyjnych, np. w bankach), oraz permissionless, udostępniane każdemu (np. blockchain bitcoinowy) [Piech (red.), 2016, s. 6].

Obszary zastosowań tej technologii są różnorakie, w tym m.in.: automatyczna realizacja kontraktów, decentralizacja gromadzenia plików i zarządzania danymi, ochrona praw autorskich, automatyzacja procesów wyborczych, zarządzanie procesami identyfikacji, zarządzanie dokumentacją medyczną, ochrona zasobów w Internecie Rzeczy (Internet of Things), automatyczna weryfikacja użytkowników (klientów), ochrona przed praniem pieniędzy itp. [How Can Blockchain Technology..., 2017].

Rzeczywiste korzyści z wykorzystania tej koncepcji są niebagatelne. Realizacja procesów staje się bardziej efektywna, bezpieczna, transparentna i tania [Taylor, 2016, s. 1-2]. Efektywna, ponieważ występują jedynie minimalne opóźnienia w realizacji transakcji w efekcie braku pośredników; bezpieczna, gdyż szyfrowanie transakcji zmniejsza ryzyko fałszerstw i błędów; transparentna, ponieważ szereg danych jest w blokach publicznych (choć dane są publiczne, to identyfikacja, kogo te dane dotyczą, nie jest publiczna); tańsza, gdyż generuje niższe koszty. Ponadto blockchain oferuje bardzo niskie bariery wejścia na rynek i znacznie zwiększa szybkość interakcji.

Często podawaną korzyścią jest uwiarygodnianie transakcji i jej uczestników. Jednym z głównych czynników napędzających rozwój tej technologii i jej atrakcyjności jest argument, że zdecentralizowana sieć nie ma centralnej jednostki zarządzającej i jest niemal niemożliwe manipulowanie nią. Z kolei kontrprzykładem jest atak na sieć Ethereum w lipcu 2016 r., gdy hakerzy wykradli transfer $50 \mathrm{mln}$ USD - nie ma zatem w 100\% pewnej technologii [How Can Blockchain Technology ..., 2017].

\section{Zastosowania w sferze finansowej}

Szczególnie obiecujące wydają się aplikacje blockchain w sektorze finansowym. Oczekuje się tu automatyzacji szeregu procesów transakcyjnych, ograniczenia kosztów danych i zwiększenia zakresu ich ochrony. Banki wdrażają systemy blockchain m.in. dla potrzeb weryfikacji użytkowników i udostępniania (wybranych) danych. Taką strategię realizuje np. BNP Paribas, wykorzystując platformę inwestycyjną SmartAngels i upowszechniając aplikacje blockchain crowdfundingu dla różnych podmiotów gospodarczych we Francji. W 2016 r. powstało konsorcjum R3 (ze wsparciem Microsoftu), którego celem jest rozwój zastosowań „łańcuchów bloków” i testowanie systemów. Do konsorcjum przystąpiło ponad 40 największych globalnych banków, w tym Bank of America, Citi, Deutsche Bank, JP Morgan. Prace nad 
wypracowywaniem nowych systemów i koncepcji trwają też w wielu korporacjach [Morabito, 2017], m.in. w Cisco, IBM, Accenture, Intel, London Stock Exchange Group, a także w wielu instytucjach ubezpieczeniowych [Maletski, Delman, 2017].

Korzyści z zastosowania analizowanej technologii są różnorakie. W szczególności wskazuje się na:

- czas realizacji procesów, zbliżony do rzeczywistego: blockchain umożliwia natychmiastowy rozrachunek transakcji, eliminację „taré” rynkowych,

- brak centralnej jednostki zarządzającej: blockchain nie wymaga uwiarygodnień uczestników rynkowych,

- zdecentralizowany rejestr, pozwalający na chronologiczne uporządkowanie transakcji,

- nieodwracalność transakcji: blockchain zawiera zweryfikowany rekord każdej dokonanej transakcji, co zabezpiecza przed dublowaniem danych, fałszowaniem i manipulowaniem,

- odporność na awarie i ataki [Deloitte, 2016, s. 4].

W tym kontekście interesujące są wyniki badań Deloitte i EFMA przeprowadzonych na grupie ponad 3 tys. respondentów, których celem było określenie, jak i w jakim zakresie technologia blockchain wpływa na usługi finansowe oraz jak podmioty gospodarcze reagują na ten rozwój. Badania jednoznacznie potwierdziły, że blockchain ma i będzie miał znaczący wpływ na usługi finansowe - zgodni są z tym twierdzeniem niemal wszyscy ankietowani (92\%), w tym $85 \%$ wskazuje na implikacje jedynie na wybrane segmenty branży. Większość respondentów (53\%) twierdzi, że oddziaływania technologii blockchain nasilą się w ciągu 2-5 lat, a kolejnych 31\% deklaruje takie implikacje w najbliższych kilkunastu miesiącach. Respondenci zgłaszają też pewne obawy związane z analizowaną technologią, w tym dotyczące niejasności prawnych (49\%) czy zakresu bezpieczeństwa (15\%) [Deloitte, 2016, s. 1,7-11]. Mimo to blockchain traktuje się jako innowacyjną technologię, a do głównych jej zastosowań respondenci zaliczają:

- międzynarodowe transfery finansowe (60\%),

- clearing i settlement (23\%),

- ochronę przed praniem pieniędzy i automatyzację procesów weryfikacji klienta (na co wskazuje co piąty ankietowany); dotychczasowa realizacja takich procesów wymagała w znacznym stopniu częstych interwencji,

- tworzenie transparentności, zabezpieczanie przed fałszerstwami, aplikacje na rynkach giełdowych, w systemach pożyczkowych, kontaktach derywatów, w monitorowaniu handlu itp. [Deloitte, 2016, s. 10].

\section{Blockchain crowdfunding}

Zalety blockchain zostały wykorzystane w crowdfundingu i w naturalny sposób doszło do integracji obu koncepcji. W efekcie ukształtował się odrębny, zdecentralizowany model finansowania społecznościowego: blockchain crowdfunding (de- 
centralised crowdfunding), niekiedy określany mianem open-sourced crowdfunding, crypto-token crowdfunding (co nawiązuje do handlu jedynie kryptowalutami) lub bitcoin 2.0 crowdfunding (w odniesieniu do koncepcji Web 2.0). Jego istotą jest gromadzenie funduszy na projekty w zamian za nagrody finansowe (cyfrowe kryptowaluty). Takie internetowe platformy umożliwiają pozyskiwanie środków finansowych przez tworzenie kryptowalut i ich sprzedaż (udziały w przedsięwzięciach).

Sądzę, że w ramach koncepcji blockchain crowdfundingu można wyodrębnić dwie główne grupy systemów:

- platformy crowdfundingu, w których dokonano implementacji technologii blockchain: mogą one spełniać różne funkcje (tj. pożyczkowe, mikrokredytowe, donacyjne, inwestycyjne bądź hybrydowe, integrujące uprzednie funkcje); obserwuje się zarówno wdrażanie takich nowych systemów, jak i proces ewolucji „tradycyjnych” systemów finansowania społecznościowego w model blockchain,

- innego typu platformy (start-upy), funkcjonujące jako blockchain, dokonujące sprzedaży kryptowalut zgodnie z procesem Initial Coin Offering; takie przedsięwzięcia mają charakter inwestycyjny.

\section{Crowdfundingowe sprzedaże kryptowalut}

Pierwotna Oferta Kryptowalut - ICO (Inicial Coin Offering), określana też skrótem ITO (Initial Token Offering), to proces, w którym sprzedawane są (przed-sprzedawane) tokeny kryptowalut i gromadzone w ten sposób środki finansowe na potrzeby uruchomienia przedsięwzięcia o charakterze inwestycyjnym. Sprzedaż następuje za waluty narodowe, najczęściej za kryptowaluty, w tym uznane (BTC, ETH). Zbywane są kryptowaluty bądź obietnica uzyskania ich w niedalekiej przyszłości. Jest to zatem spekulacja - wspierający oczekują, że ,ich” kryptowaluta będzie w przyszłości więcej warta niż obecnie i na tym zarobią. Sprzedaż tokenów (token sale, crowdsale) jest dokonywana do „thumu” internautów zgodnie z koncepcją crowdfundingu; realizowane są też przedsprzedaże (presale) kryptowalut wraz $\mathrm{z}$ upustem cenowym jako odpowiednik przedsprzedaży w modelu crowdfundingu donacyjnego z nagradzaniem. Tak jak w innych modelach crowdfundingu (zwłaszcza sponsorskim), zakres i wartości nagradzania zwiększają się - rozdysponowywane są również udziały w dochodach/zyskach start-upu, np. system FundYourselfNow.com przeznacza $70 \%$ zysków dla inwestorów.

Proces ICO jest zwykle realizowany w następujący sposób [Kastelein, 2017]. Projekt nowej kryptowaluty jest tworzony w oparciu o protokół Counterparty, Ethereum lub Openledger, a jej wartość jest arbitralnie ustalana przez jego twórców. Projekt jest szczegółowo opisywany w tzw. białej księdze (white paper), z uwzględnieniem jego celów, specyfikacji technicznej, terminów rozpoczęcia i zakończenia, ilości „waluty” do sprzedaży, biznesplanu itp. Przedsięwzięcie jest anonsowane na 
jednym $\mathrm{z}$ forów kryptowalutowych (np. Bitcointalk.org). W określonym reżimie czasowym (np. kilku tygodni) gromadzone są środki finansowe, zwykle w pieniądzu cyfrowym Bitcoin lub Ethereum.

Koncepcja ICO stała się popularną metodą finansowania projektów kryptowalutowych. Jej istotą jest sprzedaż tokenów kryptowalut „thumowi” użytkowników, grupie entuzjastów [SmithandCrown, 2016].

Metoda ICO ma charakter publiczny (jako Initial Public Coin Offering - IPCO), jest więc niekiedy porównywana z Pierwotną Ofertą Publiczną (Initial Public Offering - IPO), dokonywaną przez spółki wchodzące na giełdę. Jest tu kilka podobieństw, ale też różnic:

- obie metody są stosowane do finansowania inwestycji (sprzedaży udziałów) i pozyskiwania środków finansowych (kapitału) oraz obie poszukują inwestorów,

- odnośnie do różnic należy wskazać, że ICO jest zwykle wspierana przez grupy pasjonatów oraz inwestorów nie-profesjonalnych; zakup tokenów kryptowalut nie daje zwykle inwestorom udziałów w start-upie, lecz szanse na większy zysk (po sprzedaży tych kryptowalut); ponadto wobec ICO nie ma, jak dotąd, żadnych regulacji prawnych i wsparcia organizacji rządowych, brak jest ochrony inwestora [SmithandCrown, 2016].

Porównywanie obu metod jest możliwe, jednak ze względu na (wykluczające się) różnice nie jest wskazane. ICO jest procesem ryzykownym, liczne tego typu przedsięwzięcia się nie udały (m.in. Inchain musiał zwracać pozyskane od „inwestorów" kryptowaluty). Ryzyka wiążą się z akceptacją kryptowalut, co jest zależne np. od określonych regulacji prawnych (bądź ich braku).

\section{Segment rynkowy blockchain crowdfunding}

Dla potrzeb niniejszej pracy dokonano wydzielenia segmentu rynkowego blockchain crowdfunding i oszacowania jego rozmiarów w kategoriach globalnych. Według zaproponowanej metodyki zidentyfikowano zbiór platform elektronicznych, rozpatrując ich dwie grupy:

- funkcjonujące według modelu blockchain (tj. pożyczkowe, mikro-kredytowe, donacyjne, inwestycyjne),

- dokonujące procesu ICO (tj. sprzedaży bądź przedsprzedaży kryptowalut; takie przedsięwzięcia mają charakter inwestycyjny).

Dla każdej z platform określono lokalizację (kraj) wdrożenia i ewentualnie rok, w którym tego dokonano. Identyfikacja krajów jako lokalizacji wdrożeń okazała się szczególnie trudnym wyzwaniem, gdyż analizowane platformy z reguły funkcjonują jako globalne przedsięwzięcia - wobec tego faktografię często wyszukiwano przez bazy Whois i Crunch Base. W szczególności pozyskiwano statystyki o zgromadzonym kapitale, a wartości przeliczano na USD (dane czerpano bezpośrednio z analizowanych witryn Web lub je oszacowywano na podstawie dostępnej faktografii). Czasem pomiaru 
był dzień 18 czerwca 2017 r. Uzyskane jednostkowe wartości agregowano w kategoriach globalnych. Nie rozpatrywano systemów służących do implementacji procesów ICO dla innych podmiotów; przykładem jest gibraltarska platforma Tokenmarket.net. Nie brano pod uwagę systemów nieaktywnych, które już nie funkcjonują (np. Koinfo) lub jeszcze nie funkcjonują oraz systemów oferowanych na sprzedaż (Synerco.com).

Ogółem zidentyfikowano 118 aktywnych platform, przy czym dla 76 pozyskano lub oszacowano statystyki. Ze względów organizacyjnych jedynie 16 systemów o największych wartościach skumulowanego kapitału (ponad 16 mln USD) zestawiono tabelarycznie. Statystyki uzyskano też dla 60 innych platform (tej listy nie zestawiamy w pracy), ich skumulowane wartości zwykle były jednak niewielkie. Łącznie ta grupa pozyskała kapitał w wysokości 221975 mln USD. Sumując obie wartości, uzyskujemy kwotę przekraczającą 1 mld USD (1 $066481 \mathrm{mln}$ USD), wyrażającą rozmiary segmentu rynkowego blockchain crowdfunding.

Tab. 1. Statystyki platform blockchain crowdfunding (stan na 18 czerwca 2017 r.)

\begin{tabular}{|c|c|c|}
\hline Wyszczególnienie & Kraj (rok wdrożenia) & Zagregowany kapitał (mln USD) \\
\hline Ethereum.org/dao & SG (2015) & 160000 \\
\hline DAOhub.org (The DAO) & US (2016) & 150000 \\
\hline Blockracing.com & CN (2016) & (**) 123828 \\
\hline AEternity.com & US (2016) & $60000+$ \\
\hline MobileGo.io & GB/RU (2016) & $53000+$ \\
\hline Btsr.io & DK (2016) & $(* *) 51048$ \\
\hline SingularDTV.com & US (2016) & $(*)(* *) 50000$ \\
\hline Brave.com & US (2017) & $35000+$ \\
\hline Wayniloans.com & AR (2014) & $(* *) 34531$ \\
\hline Aragon.one & US (2016) & $25000+$ \\
\hline BTCjam.com & US (2015) & 18000 \\
\hline Qtum.org (Quantum) & CA (2016) & $(* *)(* * *) 17559$ \\
\hline Wavesplatform.com & US (2015) & $(*) 16899$ \\
\hline Lisk.io & HK (2016) & 16.841 \\
\hline Cosmos.network & $\mathrm{CH}(2017)$ & 16800 \\
\hline TokenCard.io & US (2016) & $16000+$ \\
\hline \multicolumn{2}{|l|}{ Łącznie } & 844506 \\
\hline
\end{tabular}

$\left(^{*}\right)$ szacunki własne; $(* *)$ przeliczenia kursów walut i kryptowalut; $(* * *)$ agregacja własna transakcji

Źródło: opracowanie własne z wykorzystaniem informacji z analizowanych systemów.

Największe wartości cechują systemy Ethereum.org/dao i DAOhub.org (choć w krótkim czasie wykradziono znaczną część zgromadzonych przez DAOhub środków). Chińska platforma Blockracing.com pozyskała 100 tys. BTC, będących ekwiwalentem ponad 120 mln USD. Wyszukiwarka Brave.com zgromadziła kwotę około 35 mln USD w zaledwie 30 sekund. Relatywnie dużą wartość uzyskał także polski start-up - GolemProject.net (ponad 8,5 mln USD). Platformy były oceniane w danym punkcie czasowym, dlatego zidentyfikowano również jeden system (Collabotree.com), niedawno wdrożony, w którym jak dotąd nie zgromadzono żadnych środków finansowych. 
W badanej grupie dominującymi ilościowo i wartościowo okazały się platformy realizujące sprzedaże kryptowalut, o charakterze inwestycyjnym. Mniej liczne były „tradycyjne” systemy crowdfundingu, klasyfikowane jako blockchain crowdfunding, w tym: platformy pożyczkowe (np. Wayniloans.com, BTCjam.com, BitLendingClub.com), mikro-kredytowania (WeTrust.io), donacyjne (BitHope.org), inwestycyjne (Factom.com). Zidentyfikowano także polską platformę Be-granted.com, o charakterze hybrydowym; warunkiem uczestnictwa w niej jest przekazanie donacji w kwocie 0,03 BTC, a użytkownicy mogą realizować projekty inwestycyjne, charytatywne lub sponsorskie (własne lub innych) - przykładowe projekty: spłata debetu na karcie (38 tys. USD), spłata kredytu hipotecznego (76 tys. USD), budowa górskiej restauracji (1 mln USD).

Większość wdrożeń miała miejsce w USA (43), tj. około 36\% łącznej liczby analizowanych systemów. Amerykańskie platformy wygenerowały około $42 \%$ globalnej wartości z modelu blockchain crowdfunding. Znacząco mniej implementacji zidentyfikowano w Wielkiej Brytanii (9), Szwajcarii, Kanadzie i Singapurze (po 7), Chinach wraz z Hongkongiem (5), Niemczech i Australii (po 4). Pozostała grupa krajów była miejscem 30 wdrożeń. Grupę ,pozostałe” tworzą 23 kraje, w tym: Dania, Argentyna, Słowenia, Polska, Rosja, Izrael, RPA, Holandia, Belgia, Irlandia, Finlandia, Norwegia, Hiszpania, Bułgaria, Liechtenstein, Japonia, Panama, Tajwan, Malezja, Indie, Filipiny, Kenia i Wyspy Marshalla. Można zatem stwierdzić, że koncepcja blockchain crowdfundingu znalazła zastosowanie w znacznej liczbie krajów, a ta liczba powiększa się w czasie.

\section{Podsumowanie}

Jak wykazano, rozmiary globalnego segmentu blockchain crowdfunding przekraczają obecnie 1 mld USD. To kwota niemal 5-krotnie wyższa od szacunków z roku poprzedniego, co wskazuje na dynamikę zmian rynkowych. Jednakże stanowi ona wciąż niewielki udział w łącznej skumulowanej wartości kapitału gromadzonego przez crowdfunding (według wszystkich modeli).

Koncepcja blockchain crowdfundingu, mimo niezaprzeczalnych zalet, cechuje się istotnymi zagrożeniami. Co najistotniejsze, trudno jest oceniać wiarygodność realizowanych w ramach ICO przedsięwzięć. Są one szczególnie ryzykowne zwłaszcza dla nieprofesjonalnych inwestorów, będących często jedynie entuzjastami kryptowalut. Obecnie obserwujemy niemal lawinowe wdrażanie takich systemów i koncepcja sprzedaży kryptowalut (ICO) może okazać się bańką spekulacyjną. Jak wskazano, nie ma jak dotąd żadnych regulacji prawnych i wsparcia organizacji rządowych, brak jest ochrony inwestora. Jednym z nielicznych kontrprzykładów jest platforma Tokenmarket [Kastelein, 2017] do sprzedaży tokenów kryptowalut, która nawiązała współpracę z Gibraltarską Giełdą Papierów Wartościowych w zakresie oceny wiarygodności uczestników rynków ICO czy ochrony przed praniem pieniędzy. 


\section{Bibliografia}

Deloitte, Out of the blocks. Blockchain: from hype to prototype. Report, EFMA, 2016.

Dziuba D.T., Rozwój systemów crowdfundingu - modele, oczekiwania i uwarunkowania, „Problemy Zarządzania" 2012, nr 3.

How Can Blockchain Technology Companies Become More Competitive, 2017, www.chipin.com/blockchain-technology-competitive-companies [dostęp: 21.04.2018].

Kastelein R., What Initial Coin Offerings Are, and Why VC Firms Care, "Harvard Business Review" 2017 (March).

Maletski G., Delman Z., Blockchain's Benefits for Insurers. Begin Planning for The Next Blockbuster Technology, 2017, www.sapiens.com/wp-content/uploads/2017/02/WP_Blockchains-Benefits-for-Insurers_RevC.pdf [dostęp: 10.03.2018].

MarketsandMarkets, Blockchain Market by Provider \& Application - 2021. Report TC 4638, Marketsandmarkets.com, 2016.

Morabito V., Business Innovation Through Blockchain: The B3 Perspective, Springer, 2017, DOI: https://doi.org/10.1007/978-3-319-48478-5.

Piech K. (red.), Leksykon pojęć na temat technologii blockchain i kryptowalut, Ministerstwo Cyfryzacji, Warszawa 2016.

SmithandCrown, What is a token sale (ICO)?, 2016, www.smithandcrown.com [dostęp: 10.03.2018].

Taylor J., $21^{\text {st }}$ Century Digital Funds, 2016, www.applebyglobal.com/publication-pdf/article/2016/21st-century-digital-funds-(jtaylor)-may-2016.pdf [dostęp: 10.03.2018].

\section{The Blockchain Crowdfunding Technology: Usage, Benefits, and Expectations}

The paper presents the blockchain crowdfunding technology and its economic implications. It is a separate, decentralized model of social funding, based on "block chains", growing in response to technological progress, as well as to expectations of IT users with respect to the increasing popularity of cryptocurrencies and the demand for new categories of systems. The essence of the blockchain technology is presented, along with the potential benefits and the variety of applications, especially in the field of banking and finance. The blockchain crowdfunding model and the Initial Coin Offering process are described. Furthermore, the global blockchain crowdfunding market segment is estimated and analyzed. The main benefits and factors (risks) of the model are identified, as well as its growth prospects.

\section{Technologia blockchain crowdfunding: zastosowania, korzyści i oczekiwania}

W artykule przedstawiono koncepcję blockchain crowdfundingu i wynikające z niej implikacje gospodarcze. Stanowi ona odrębny, zdecentralizowany model finansowania społecznościowego, bazujący na „łańcuchach bloków”, i jest efektem rozwoju technologicznego oraz oczekiwań użytkowników IT co do upowszechniania kryptowalut i wdrażania nowych kategorii systemów. Zaprezentowano istotę technologii blockchain, potencjalne korzyści i różnorodność zastosowań, zwłaszcza w sferze finansowo-bankowej. Umożliwiło to opisanie modelu blockchain crowdfundingu i związanego z nim procesu pierwotnej emisji kryptowalut (Initial Coin Offering). Dokonano też oszacowania i analizy globalnego segmentu rynkowego blockchain crowdfundingu oraz zidentyfikowano główne korzyści i uwarunkowania (ryzyka) wiążące się $\mathrm{z}$ badaną koncepcją, a także perspektywy jej rozwoju. 